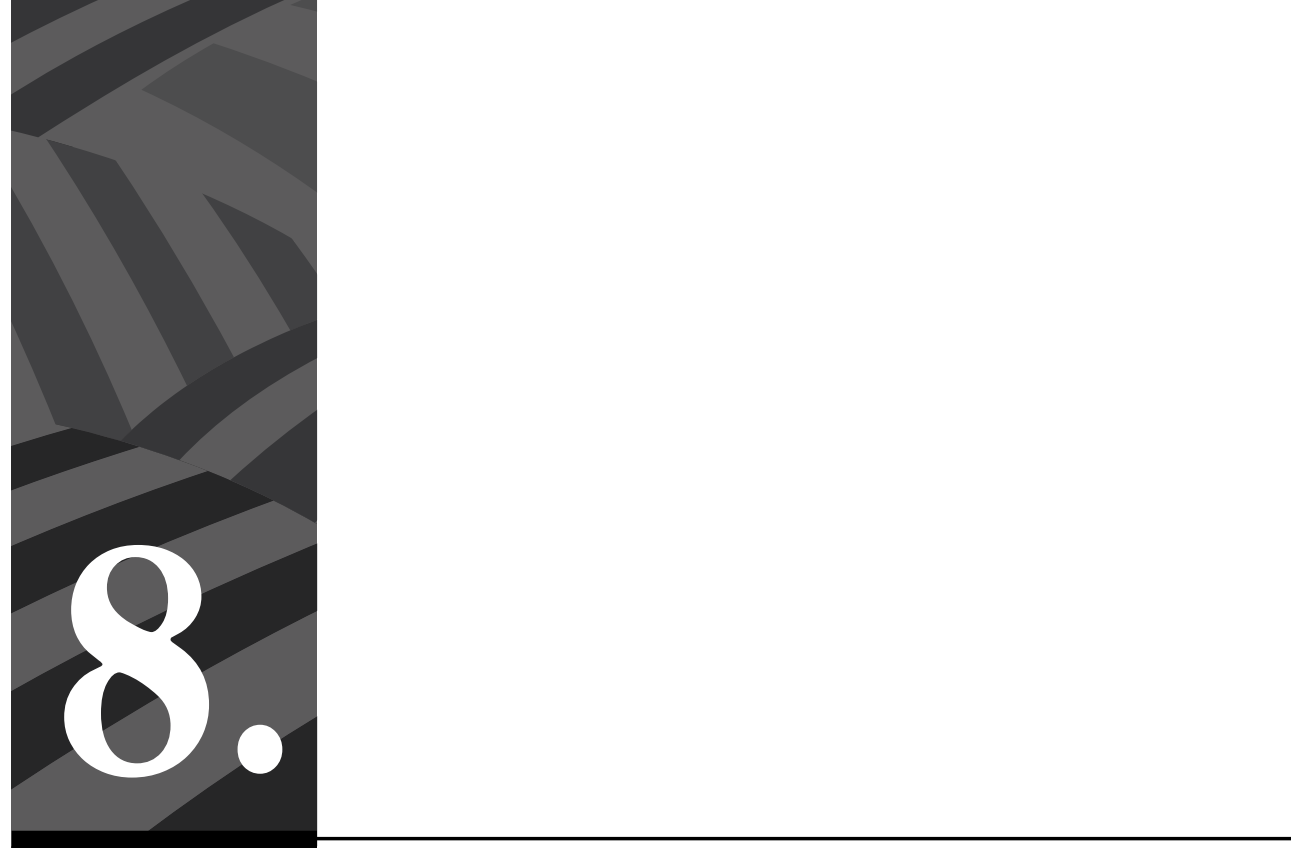

Pandemia en un contexto gore.

Un análisis necropolítico de Tumaco 


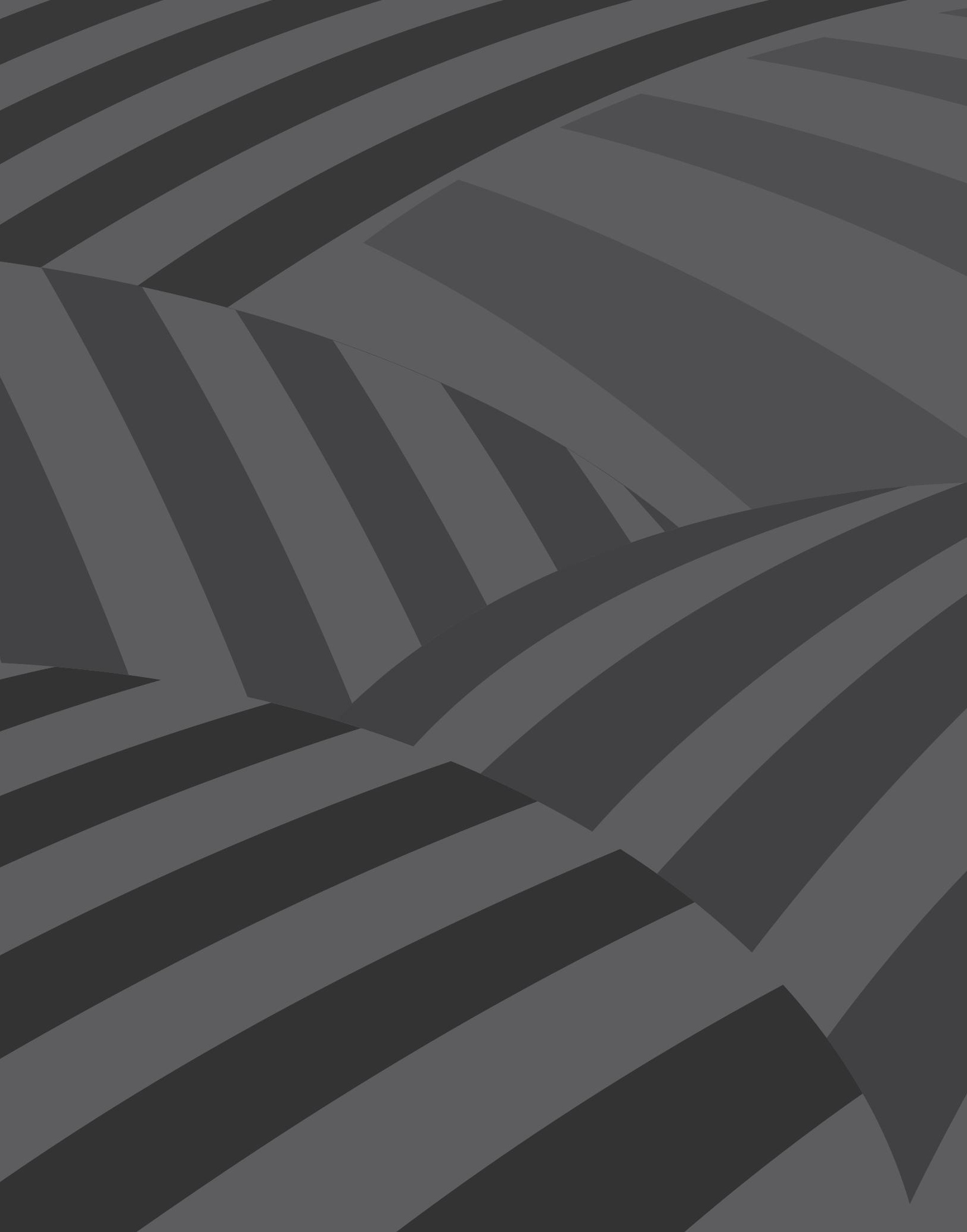




\title{
Pandemia en un contexto gore. Un análisis necropolítico de Tumaco
}

\author{
Por José Mario Suárez*, Karina Alexandra Gómez**
}

Resumen: La desigualdad estructural, profundizada por el proyecto neoliberal, a la cual han sido sometidas muchas regiones de América Latina como el Pacífico colombiano, ha contribuido a la configuración de un contexto de vulnerabilidad en el que convergen múltiples violencias, cuyos efectos se recrudecen durante las crisis humanitarias. Este artículo tiene como propósito examinar, desde el análisis documental, algunos de los impactos de la pandemia de COVID-19 en Tumaco, bajo una lectura de necropolítica y capitalismo gore propuestos por Achille Mbembe (2011) y Sayak Valencia (2010). A partir de este análisis, se concluye que la condición geográfica de border, asociada al desarrollo de mercado que cohabita con profundas estructuras de desigualdad socioeconómica y violencias, multiplica los riesgos sobre ciertas vidas en momentos de crisis. Geografías de pobreza, participación de sujetos endriagos y circulación de mercancías ilícitas, recrudecen los ejercicios necropolíticos contra cuerpos afrodescendientes.

Palabras clave: Tumaco, necropolítica, border, COVID-19, violencia.

\section{Pandemic in a Gore context. A necropolitical analysis of Tumaco}

Abstract: The structural inequality, intensified with the neoliberal project, to which many regions of Latin America such as the Colombian Pacific have been subjected, has contributed to the configuration of a context of vulnerability in which multiple types of violence converge, whose effects worsen during humanitarian crises. The purpose of this article is to examine, from a documentary analysis, some of the impacts of COVID-19 in Tumaco under a reading of Necropolítica y Capitalismo Gore proposed by Achille Mbembe (2011) and Sayak Valencia (2010). From this analysis, it is concluded that the geographic border condition, associated with the development of the

* Sociólogo por la Universidad Nacional Autónoma de México, estudiante de la Maestría en Estudios Sociales y Políticos de la Universidad Icesi. Asistente de Investigación Centro de Estudios Afrodiaspóricos. Correo electrónico: mariosuarezmarti@gmail.com

* Economista por la Universidad Nacional de Colombia, estudiante de la Maestría en Estudios Sociales y Políticos de la Universidad Icesi. Asistente de Investigación del Centro de Estudios Afrodiaspóricos. Correo electrónico: kgomexg@unal.edu.co 
market that coexists with deep structures of socioeconomic inequality and violence, multiplies the risks to certain lives in moments of crisis. Geographies of poverty, the participation of sujetos endriagos and the circulation of illicit merchandise intensify the necropolitical exercises against Afro-descendant bodies.

Keywords: Tumaco, necropolítica, border, COVID-19, violence.

Cómo citar este artículo: Suárez, José Mario; Gómez, Karina Alexandra (2021). Pandemia en un contexto gore. Un análisis necropolítico de Tumaco. Revista Controversia, 216, 257-285.

Fecha de recepción: 28 de septiembre de 2020.

Fecha de aprobación: 21 de noviembre de 2020.

\section{Introducción}

$1 \begin{aligned} & \text { ientras analizábamos la importancia de la necropolítica en los } \\ & \text { contextos latinoamericanos a la luz de los fenómenos socioló- } \\ & \text { gicos contemporáneos, descubrimos la imperiosa necesidad de }\end{aligned}$ aterrizar elementos teóricos y conceptuales para pensar las realidades periféricas que también atraviesan nuestras biografías como investigadora y como investigador. Estas realidades múltiples y contradictorias conviven entre una condición geográfica de riesgo y una contención de grupos humanos racial, sexual ${ }^{1} \mathrm{o}$ interseccionalmente definidos. Una de esas realidades y lugar de origen de Karina Alexandra Gómez, coautora de esta investigación, es Tumaco, la Perla del Pacífico.

El municipio de Tumaco ha sido ampliamente analizado en estudios sobre el modo como están relacionadas sus dinámicas locales de despojo estructural rural y urbano, la violencia ejercida por sujetos armados y grupos criminales, ${ }^{2}$ y la presencia de profundas desigualdades que

1 Anticipamos lo sexual bajo una lectura de género, en donde lo femenino es construido socialmente (Zúñiga, 2018).

2 Entendemos la complejidad de los grupos armados en la zona. Por ahora, asumimos una definición extendida de este tipo de sujetos, independientemente de su participación en células como las AUC, las FARC, o incluso cárteles mexicanos. Consideramos 
caracterizan este y muchos otros municipios del Pacífico colombiano (Fundación Ideas para la Paz, 2014). Esta producción socioespacial hoy convive, como en todos los países de la región, con la pandemia de COVID-19 y sus múltiples y crueles pedagogías.

La presente investigación es producto de un análisis documental, acompañado de un entramado conceptual que describe las múltiples violencias en un contexto gore, que pueden cohabitar con momentos de crisis tales como el de la pandemia de COVID-19. La estructura argumentativa está dividida en tres apartados. En el primero, intentamos situar conceptualmente la pertinencia de los planteamientos del capitalismo gore y de la necropolítica, para entender las violencias suscitadas en la región contra ciertos cuerpos; el segundo procura brindar al lector una visión panorámica - geográfica y racial- de Tumaco desde tres características fundamentales: la geografía de la pobreza, la presencia de sujetos endriagos ${ }^{3}$ y su condición border, ${ }^{4}$ partiendo fundamentalmente del casco urbano; por último, analizamos la coyuntura pandémica actual a la luz de algunos elementos anteriormente planteados, para reflexionar sobre los impactos específicos de este fenómeno en la región. Concluimos con algunas anotaciones sobre la complejidad de la necropolítica en la región y algunos de los retos que arroja para posteriores investigaciones.

que la producción de las violencias y la agencia en el orden de lo ilegal, amparado en el border, es una definición amplia que permite analizar las dinámicas de una forma integral como propuesta conceptual. Sostenemos entonces que, al intentar construir un análisis conceptual y bibliográfico, nos distanciamos para esta investigación de la complejidad de los actores armados que tienen presencia en la zona.

3 Individuos o colectivos en contextos de riesgo, con capacidad de generar prácticas de violencia que oscilan entre la propagación del miedo e incluso el aniquilamiento físico.

4 Frontera, en español. Sayak Valencia (2010) opta por analizar esta categoría en inglés por dos razones: a) como una descripción física de la frontera entre México y Estados Unidos, con una clara ventaja geopolítica para el segundo; y b) como metáfora de un espacio límite en donde coexisten elementos que oscilan entre la legalidad y la ilegalidad. 


\section{Necropolítica en la región}

En 2010, la mexicana Sayak Valencia acuñó el término capitalismo gore con una influencia importante de las ideas sobre el biopoder desarrolladas por Michel Foucault y la posterior propuesta de necropolítica de Achile Mbembe. Este concepto es una invitación a repensar las contradicciones del proyecto neoliberal, que se cristalizan en prácticas tanáticas ejercidas fundamentalmente contra las mujeres ${ }^{5} \mathrm{y}$ contra todo sujeto que pueda ser objeto de estos ejercicios de muerte, llámese indio, migrante, subalterno o negro, en un contexto de frontera (border) capitalista periférico.

Si bien el análisis concreto de la autora se centra en la frontera entre México y Estados Unidos de América, la similitud de los borders latinoamericanos arroja elementos para asumir una cierta aplicabilidad comparativa tanto de los sujetos vulnerados como de las prácticas ejercidas sobre ellos. Tanto la frontera en el norte, cimiento del estudio de caso de la autora, como la frontera en el sur entre Ecuador y Colombia, unidad de interés de nuestra investigación, comparten a) su condición periférica espacial y b) la existencia de conflictos internos con una presencia protagónica del narcotráfico en la zona. En términos socioespaciales, la condición periférica de ambos países está definida por una construcción espacial que caracteriza la "desterritorialización del Tercer mundo" (Valencia, 2010, p. 168), un modelo de mercado, y la producción

5 Si bien no es parte del análisis de la presente investigación, cabe aclarar que, como las mujeres obreras en México, en la frontera sur las mujeres negras sufren violencias específicas en este tipo de contextos, donde son despojadas de sus individualidades para integrarse en los esquemas de dominación de actores armados. Estas mujeres, pertenecientes a los barrios más marginados del territorio -en condiciones de precariedad, pobreza o ausencia de un núcleo familiar sólido-, son engañadas por medio de regalos o promesas que en un inicio parecen garantizarles una vida con mejores condiciones, para luego ser sometidas a una serie de violencias que, como menciona Betty Lozano (2016), representan un continuum de terror antifemenino que incluye abusos, ya sean verbales o físicos; y hechos como violación, tortura, prostitución obligatoria, siendo incluso expuestas a maltrato público como mecanismo de control e intimidación (Lozano, 2016, p. 2). 
de subjetividades y de sujetos endriagos de consumo. ${ }^{6}$ Sobre este tercer mundo, la necropolítica, heredera de los planteamientos biopolíticos y del biopoder, ${ }^{7}$ opera como la manera primordial de lo político que describe una forma de separar las vidas que valen de las que no (Estévez, 2018). Esta política actúa como poder sobre los cuerpos, donde su cuidado, conservación, libertad e integridad se ofrecen como productos; lo político como condición de muerte está justificado a través de quién merece vivir y quién merece morir (Mbembe, 2011). En cuanto concepto, la necropolítica es definida en tanto:

Un poder que crece a través del estado de excepción, generando la reducción del ser humano por medio de una precarización existencial, una vida sin sujeción política, una nuda vida en contraposición con el bios, donde la vulneración y uso predatorio del cuerpo se vuelve indispensable para su incorporación al mercado neoliberal, hiperconsumista. (Valencia, 2010, pp. 139-140).

Por su parte, el capitalismo legal e ilegal le agrega una condición de mercado a las fronteras en donde

los cuerpos de los disidentes distópicos y los ingobernables son ahora quienes detentan [...] el poder que se ejerce sobre el cuerpo individual y sobre el cuerpo de la población, creando un poder paralelo al Estado sin suscribirse plenamente a él, al mismo tiempo que le disputan su poder de oprimir. (Valencia, 2010, p. 143).

6 La efectividad del necropoder radica en las necroprácticas ejercidas por sujetos endriagos; estas son acciones radicales encaminadas a vulnerar corporalmente, entre las cuales se encuentra la reapropiación de los medios de eliminación de los enemigos del Estado aplicados a los enemigos de los sujetos endriagos [...], posibilitando así las formas de crueldad más tajantes y espeluznantes que puedan espectralizarse por medio de su consumo como ocio televisado y espectáculo. (Valencia, 2010, p. 147).

7 Entendemos la biopolítica como el control sobre la vida y sobre la población como problema político y problema de poder, mediante dispositivos discursivos con la demografía, la estadística y la medicina que tiene entre sus objetivos el cálculo de la vida (López, 2014). 
Esta violencia ejercida desde los sujetos, quienes ahora gobiernan de la mano con el Estado que actúa de forma paralela, revela una concepción clásica del racismo de Estado definido como "la protección que hacen los Estados modernos de la integridad social mediante técnicas normalizadoras de purificación permanente del cuerpo" (Foucault, 2001, p. 154). Las prácticas criminales permanecen entonces unidas a los gobiernos y protegidas por ellos.

Del otro lado, estas violencias son posibles y justificadas gracias a la reproducción simbólica de discursos que construyen y multiplican los prejuicios sobre aquellos sujetos en los que recaen estas prácticas, bajo la construcción del enemigo interno o indeseable (Van Dijk, 1997) del que el cuerpo social se debe purificar. ${ }^{8}$ Este tipo de violencia discursiva se encuentra amparada en la participación que los sujetos objeto de las necroprácticas habrían tenido en los hechos criminales, desde una presunta responsabilidad como actores de los grupos implicados en los fenómenos, o de la posible conexión como sujetos asociados típica e históricamente a hechos de violencia (Zaffaroni, 2012).

Esta es una de las premisas fundamentales del capitalismo gore: los sujetos objeto de las necroprácticas comparten el prejuicio ${ }^{9}$ de posible criminalidad “a través de estereotipos, que configuran un 'ellos' separado del resto de la sociedad [...], las muertes son naturalizadas

8 Sobre esto destacamos la reproducción de comentarios y prejuicios racistas en las plataformas como YouTube y Facebook, con ejemplos como "pinches negros merecen morir”. Para profundizar en esta reproducción mediática del racismo se recomienda mirar el artículo de Carlos Valderrama (2015), disponible en https://www. las2orillas.co/estilos-formas-del-racismo-mediatico-la-colombiana/

9 Esta proliferación simbólica de la violencia centrada en la reproducción de discursos de odio ha sido ampliamente analizada con los feminicidios ocurridos en México, que generalmente acontecen en espacios periféricos permeados por lógicas sicariales (Vasil'eva, Centmayer, Del Valle y Maya, 2016). La producción de los rumores y la noción de responsabilidad prevén y engrosan la idea de una presunta participación delictiva de las víctimas, reduciendo en muchas ocasiones el discurso a la afirmación “seguro andaba en malos pasos” (Tercero, 2013). 
y normalizadas con un alto grado de encubrimiento de las causas de sus muertes" (Gusis, 2018, p. 284).

Estas múltiples violencias ocurren en territorios específicos que, a pesar de que tienen una participación en las economías legales e ilegales, se definen por altos niveles de pobreza y de vulnerabilidad similares al Township, un lugar caracterizado por la pobreza con una profunda lógica de raza y clase (Álvarez, 2013).

La violencia aparece como un fenómeno físico y como producción cultural, convirtiéndose en una herramienta para producir riqueza que está siendo globalizada en la medida que se "entreteje con la creación de una subjetividad” (Valencia, 2010, p. 174).

Es en el plano de lo cultural y de la reproducción de los discursos sobre ciertos sujetos, que no solo se justifica la muerte de mujeres, indígenas o disidentes, sino que también se invisibilizan las características estructurales que caracterizan ciertas geografías, ponderando la responsabilidad de las víctimas sobre la estructura necropolítica de interés.

Si bien parece que la violencia directa describe una participación evidente del Estado, ${ }^{10}$ así como en lo cultural opera la reproducción de las subjetividades racistas, en la instauración del biopoder el Estado actúa multiplicando las condiciones de riesgo para ciertas poblaciones, sobre lo cual Giraldo propone que:

"Matar" no se refiere solamente al asesinato directo, sino también a todo lo que puede ser muerte indirecta, es decir, al hecho de exponer a la muerte o de multiplicar para algunos el riesgo de muerte, o más simplemente la muerte política, la expulsión. (2006, p. 107).

10 El racismo de Estado es definido por Foucault como "la protección que hacen los Estados modernos de la integridad social mediante técnicas normalizadoras de purificación permanente del cuerpo" (2001, p. 154). 
Así, el desamparo desde el Estado de ciertos sujetos en algunas geografías, expulsándolos y despojándolos de condiciones humanas de existencia, cohabita con todo un aparato necropolítico y con muchas otras lógicas de violencia estructural.

Es en este último nicho donde se concentra la otra violencia: la étnica (Vera, 2015), aquella que también multiplica los riesgos al interior de las lógicas gore, sustentada por todos los entramados expuestos. La violencia étnica es definida como la "utilización de las diferencias y los contrastes como base para crear desigualdades [...] esta violencia está amparada en una superioridad-inferioridad ideológica y estructural que suele afectar a las llamadas minorías étnicas” (Moreno, 1994, p. 156).

La participación del Estado en este tercer tipo de violencia parte de la producción histórica de la invisibilidad de los grupos racializados y va hasta la omisión de su responsabilidad en momentos coyunturales -que afectan tanto el Norte como el Sur Global ${ }^{11}$ - y la diversidad de sus efectos en distintas poblaciones que merecen especial protección, siendo en este momento el fenómeno transnacional la pandemia de COVID-19. ${ }^{12}$

Sobre el último punto y con el objetivo de exponer el segundo apartado de esta investigación, surge la pregunta: ¿Cuáles son las condiciones estructurales necropolíticas y gore que cohabitan con la pandemia en Tumaco?

11 De Souza Santos y Meneses (2016) son dos de los teóricos sobre epistemologías del sur que han trabajado los conceptos de Norte Global y Sur Global. El primero abarca a los países "desarrollados" que desde hace casi 500 años encaminaron procesos de colonización tanto física como social y política. El segundo alude a los países periféricos que sufrieron ese tipo de colonizaciones y que han decantado en formas profundas de sometimiento capitalista, colonial y patriarcal.

12 En el nombre abreviado, CO corresponde a corona, VI a virus y $\mathrm{D}$ a disease (enfermedad). 


\section{Hacia un perfil sociodemográfico y necropolítico de la Perla del Pacífico}

Tumaco, como muchos territorios del Pacífico colombiano, lucha contra unas desventajas acumulativas que se manifiestan a través de la reproducción de desigualdades socioeconómicas y dinámicas de guerra producto del abandono estatal; esto ubica a la población en situaciones de pobreza, zozobra y una vulnerabilidad constante y permanente. Como el área urbana ${ }^{13}$ más importante de la costa nariñense, este municipio cuenta con una población de aproximadamente 200000 habitantes, en su mayoría afrodescendientes (Departamento Administrativo Nacional de Estadística [DANE], 2005), ${ }^{14}$ y a lo largo de su extensión territorial concentra una geografía humana racializada que sobrevive en medio de una estructura necropolítica, donde la soberanía se ejerce en función del derecho a dar muerte como mecanismo de control (Alves, 2020). Para analizar su perfil proponemos tres ejes sustanciales.

\section{a) Geografía de la pobreza}

La geografía de la pobreza ${ }^{15}$ hace referencia a la distribución espacial de las desigualdades. Para su definición conceptual se toman como eje central las diferenciaciones socioespaciales en cuanto parte de los procesos de destitución social y determinantes de la concentración geográfica de la pobreza, es decir, se exploran las desventajas acumulativas en espacios de privación intensa (Lupton y Power, 2002, citado por López, 2017, p. 10).

13 Una definición técnica del área urbana la explica como el área territorial conformada por conjuntos de edificaciones y estructuras contiguas agrupadas en manzanas, las cuales están delimitadas por calles, carreras y avenidas, principalmente. Cuenta, por lo general, con una dotación de servicios esenciales tales como acueducto, alcantarillado, energía eléctrica, colegios. En esta categoría están incluidas las ciudades capitales y las cabeceras municipales (DANE, 2000, p. 1). Coloquialmente estas zonas son conocidas entre los habitantes como casco urbano.

14 Se toma como referencia el Censo de 2005, dadas las dificultades de aspecto metodológico presentadas en el Censo del 2018 con respecto a la población negra.

15 Este término toma relevancia a partir de la década de los noventa, con los esfuerzos del Banco Mundial por erradicar la pobreza extrema de ciertos territorios. 
Desde esta perspectiva, se han identificado zonas a nivel mundial que se han constituido en clústeres de pobreza habitados por personas con características fenotípicas concretas. Si analizamos globalmente las áreas pobres, encontramos que el mayor clúster de pobreza está ubicado en el continente africano, un territorio con escaso equipamiento, donde sus habitantes poseen un fenotipo específico que corresponde a rasgos negros, la mayoría de sus países tienen un aparato político inestable y las necesidades básicas están completamente insatisfechas (Oya y Sender, 2007). En ese sentido, el contexto de América Latina y el Caribe no es distinto: países como Haití o Brasil demuestran la vigencia del necropoder y la biopólis ${ }^{16}$ en esta parte del mundo. En Colombia, regiones como el Pacífico y el Caribe, o zonas de ciertas ciudades como el Distrito de Agua Blanca en Cali, revelan las coordenadas del biopoder contra ciertos cuerpos (Alves y Ravidran, 2018).

Por lo tanto, es posible deducir que el aspecto étnico-racial juega un papel fundamental en la geografía de la pobreza. Es decir, la raza socialmente construida cumple un rol esencial que, como una forma de control, presupone una distribución de la especie humana en diferentes grupos y el establecimiento de una ruptura idealizada entre unos y otros, convirtiéndose en un elemento constitutivo del pensamiento y las prácticas de las políticas occidentales. En clave de capitalismo gore, estos espacios son construidos a partir de la interacción de sujetos (mujeres y hombres) que históricamente han sido clasificados como inferiores. Sujetos marginados, excluidos y en medio de la precariedad participan directa o indirectamente en ambientes altamente violentos que terminan en prácticas de muerte. Por ello, estas geografías de la pobreza, entendidas como una forma de ejercer la política de la raza, ${ }^{17}$ permiten construir espacios donde opera, también, una política de la muerte.

16 Jaime Alves propone la idea de biopólis como una producción de la ciudad con un profundo ejercicio de biopoder, en el cual los cuerpos negros son los más vulnerados en clave de racismo estructural. A pesar de que en la ciudad existen profundas violencias y desigualdades, los cuerpos negros tienden a sufrir mayores niveles de violencia.

17 Reiteramos el uso argumentativo de la raza como elemento socialmente no construido y no como elemento biológicamente definido. 
En términos estadísticos, el Pacífico cuenta con una tasa de incidencia de la pobreza correspondiente al 33,8\%, cifra que está por encima de la tasa nacional $(20,2 \%)$ y la tasa de la región andina ${ }^{18}(22,1 \%)$ (Galvis, Moyano y Alba, 2016). Para el caso de Tumaco, principal puerto petrolero en la costa Pacífica, el 48,74\% de quienes viven en la zona urbana se encuentran con necesidades básicas insatisfechas (NBI) y el 16,73\% viven en condiciones de miseria. En la zona rural, alrededor del 59,32\% de la población vive con NBI y el $25,90 \%$ en condiciones de miseria (DANE, 2005). Sumado a esto, el índice de pobreza multidimensional en el municipio es de $84,5 \%$, no hay carreteras suficientes, hay carencia de agua potable, la cobertura de salud y educación es mínima, y el descuido y el abandono son evidentes.

Estas condiciones de exclusión obligan a la población a estar en constante lucha por sobrevivir y adaptarse al sistema, creando dinámicas económicas que instauran nuevas formas de control a través del derecho a matar y que, a su vez, se suman a las formas de control ya existentes. Estas condiciones se cristalizan en fenómenos como el narcotráfico, que se erige en una de estas nuevas economías y formas de insertarse en las lógicas del sistema capitalista ${ }^{19}$ (Valencia, 2010).

18 Donde la mayor parte de la población se concibe bajo la categoría blanca-mestiza.

19 Hoy, Tumaco es el municipio con mayor número de hectáreas de coca cultivadas. En el año 2017 batió récord, con el 18\% del total de hectáreas cultivadas en el país, las cuales son cosechadas en la zona rural que limita con el Ecuador, según datos del Sistema Integrado de Monitoreo de Cultivos Ilícitos-Oficina de las Naciones Unidas contra la Droga y el Delito (2018). Paradójicamente, la Perla del Pacífico está entre el privilegio y la condena de contar con abundancia de recursos naturales; su ubicación geográfica, sus complejos ecosistemas de manglar, la exclusión territorial y su posición fronteriza la convierten en un paraíso perfecto, en donde el desarrollo del narcotráfico es un imán ineludible para las bandas criminales, disidencias de las FARC, fuerzas militares estatales y grupos paramilitares, que actúan como maquinaria de guerra por el control rural y urbano de este territorio (Fundación Paz y Reconciliación, 2016, citado en Bitácora \& Territorio, 2017). 


\section{b) Sujetos endriagos}

El olvido por parte del Estado legal, la introducción de políticas neoliberales excluyentes y la adopción del narcotráfico como una respuesta para insertarse en las lógicas del capital, han contribuido a la organización de una clase criminal que lucha por sus propios intereses y que está conformada por jóvenes en condiciones de pobreza y desempleo permanente. Sayak Valencia (2010) categoriza este grupo social como sujetos endriagos, definiéndolos como individuos marginalizados con capacidad de generar terror por medio de prácticas de miedo y muerte, como oficinas de sicariato, secuestros y torturas, a favor de legitimación económica y reconocimiento social a través de apodos como el Patrón, el Duro o "el que manda". Ellos se convierten en el instrumento mediante el cual el capitalismo gore cobra vida en este territorio.

Es así como la desigualdad de oportunidades y la ausencia de garantías de seguridad han llevado a que estos jóvenes vean la pertenencia a la clase criminal como alguna de las opciones de subsistencia, convirtiéndolos en sujetos que dan muerte para sembrar terror. Bajo este contexto, la racionalidad propia de la vida pasa a ser necesariamente la muerte del otro, lo cual está en función de la capacidad de matar para vivir (Salazar, 2014). Este fenómeno se manifiesta en las formas de control ejercidas en las calles y la disputa de barrios pobres como el Nuevo Milenio, Viento Libre, Buenos Aires y el sector de los Puentes, lugares donde al estilo de la película Ciudad de Dios (2002) se normaliza el porte de armas de fuego por parte de jóvenes menores de edad y la presencia de campane$\operatorname{ros}^{20}$ en sitios estratégicos para vigilar el flujo de personas que ingresan en estas zonas de fronteras invisibles. Aquí se generan prácticas de necropolítica como la extorsión, la muerte, los asesinatos, las torturas y el

20 Este término hace referencia a las personas que participan en las lógicas sicariales y cumplen la función de avisar o campanear sobre cualquier anormalidad que se presente en la zona controlada por algún actor armado que ponga en riesgo la zona o la economía gore. 
descuartizamiento, lo que muestra características específicas de reproducción local de la violencia y el consumo de la narco-cultura que, entre muchos de sus efectos, ejerce dominación simbólica fundamentalmente contra cuerpos racializados o mujeres víctimas de la violencia.

Como menciona Betty Lozano (2016) siguiendo la producción de las violencias distópicas, son estos hombres del terror quienes imparten zozobra extrema en el territorio y oprimen despiadadamente a mujeres en condición de pobreza y vulnerabilidad. ${ }^{21}$

Esta producción de violencias entre victimas-victimarios representa una transvaloración de valores y prácticas en estos territorios, que se reflejan en la deshumanización de la vida misma y cuyo soporte está basado en la mercantilización de la muerte, que termina siendo clave para la acumulación de capital en estos entornos (Valencia, 2010).

De este modo, se evidencia que los cuerpos humanos son concebidos como productos de intercambio que, en manos de estos sujetos, se convierten en mercancía; es decir, se produce una industrialización de la muerte. ${ }^{22}$

21 Para el caso de los cuerpos femeninos y racializados, el sometimiento pasa por aspectos aparentemente superficiales, reproduciendo la cosificación e hipersexualización histórica. Para aterrizar empíricamente esto, resulta pertinente mencionar el caso de las tres adolescentes que aparecieron muertas en la zona de manglar del Pindo. Una de ellas vivía en Viento Libre y las otras dos residían en el sector de los Puentes; estos barrios, como se mencionó en líneas anteriores, son altamente peligrosos y controlados por organizaciones criminales. De acuerdo con la investigación que adelantó la Fiscalía, el presunto asesino de las adolescentes fue asesinado por la organización que manejaba la ruta del tráfico de drogas en el municipio para ese momento (Periódico La Última, 2016). Otro ejemplo son los hechos de maltrato público hacia una adolescente de aproximadamente 16 años, presenciados en diciembre de 2019 en el barrio Nuevo Milenio, y en los que la joven fue violentada físicamente por un joven relacionado con la organización que maneja la zona. Los golpes y amenazas de muerte con arma de fuego en presencia de la multitud fueron utilizados como instrumento de sometimiento; sus palabras exigían obediencia a cambio de la muerte y las de ellas clamaban perdón a cambio de la vida; ninguno de los espectadores se atrevió a involucrarse en el hecho, por temor a su integridad (Beiron, comunicación personal, 2020).

22 Por ejemplo, durante el periodo comprendido entre 2010 y 2012 murieron muchas personas, como don Armando Cabezas, quien era motorista, padre de familia y 


\section{c) Condición border}

Estos elementos tanto geográficos en coordenadas locales como desde los sujetos que encarnan las violencias tienen una conexión directa con las dinámicas geopolíticas que se presentan en la frontera. De acuerdo con el diario El Comercio (2017), a través de esa zona fronteriza se envía entre el 60 y el $70 \%$ de toda la droga que se exporta de Colombia hacia Estados Unidos, utilizando las vías fluviales entre los ríos Mataje y Mira como canales. Aquí, al igual que en la zona urbana, hay presencia de sujetos endriagos, quienes han encontrado en las prácticas criminales, transversalizadas por estas ultraviolencias, una alternativa para crear capital y cumplir con los parámetros exigidos por la economía de mercado. En estos casos, son el cultivo, el transporte y la comercialización, como economía ilegal, los elementos que suplen sus necesidades básicas e indirectamente las necesidades de la mayor parte de la población; en otras palabras, la condición border facilita la dinamización de todo el comercio de la zona y promueve significativamente el fortalecimiento de la infraestructura para la producción y transporte de cocaína, con una ventaja absoluta por su ubicación geográfica.

De esta economía se deriva gran parte de la situación de violencia que sufre actualmente el municipio, y que en gran medida está relacionada con la implementación del Acuerdo de paz para la terminación del conflicto y la construcción de una paz estable y duradera, específicamente con el punto 4. Solución al problema de las drogas ilícitas, que incluye la sustitución de cultivos ilícitos y, por tanto, la disminución de las confrontaciones constantes entre grupos armados de la zona rural fronteriza, donde se implementa dicho acuerdo (Angulo y López, 2018). Esta dinámica que se vive en la zona rural no puede ser desligada de lo que sucede en el casco urbano, pues encontramos un efecto en la primera que se ve reflejado en el segundo, como en el caso de Tumaco. Aquí, el

comerciante muy conocido en el barrio Nuevo Milenio, y fue asesinado por negarse a pagar una vacuna o extorsión en su negocio (Beiron, comunicación personal, 2020). Como él, muchas personas murieron en las mismas condiciones. 
Estado necesita mayor capacidad administrativa, incluso en el análisis geopolítico de las fronteras y los ciudadanos. ${ }^{23}$

La anterior tipificación desemboca en la intensificación de diferentes tipos de violencias; por un lado, las violencias producidas por el crimen organizado y, por el otro, la violencia étnica ejercida por el Estado al someter a este municipio a condiciones precarias (Vera, 2015): ambos elementos coadyuvan al exterminio paulatino de la población. De forma piramidal, este complejo proceso puede sintetizarse como se muestra en la figura 1.

\section{Figura 1. Pirámide efectos de la necropolítica en el nivel regional con la participación geopolítica, nacional con la producción de sujetos de violencia al interior del Estado legal e ilegal y local desde los impactos específicos que tienen los dos niveles anteriores.}

Dinámicas transnacionales con efectos en la región. Mercado neoliberal de sustancias ilícitas en donde operan las fronteras con a) cultivos ilícitos; y b) puertos estratégicos de distribución hacia Norteamérica, Centroamérica y Sudámerica.

Proyecto necropolítico en el border tumaqueño
Dinámica nacional con efectos en Colombia. Mercado nacional e impactos en la cultura de la violencia gore, mediante la producción de sujetos endriagos que participan desde el Estado legal o ilegal. Estos agentes multiplican los bandos criminales y construyen necroprácticas.

Dinámica local con efectos en Tumaco. Efectos del proyecto neoliberal y la producción de sujetos endriagos sobre poblaciones con un profundo marcador étnico-racial. Dichas violencias recrudecen y multiplican las vulnerabilidades a las que se enfrenta esta población.

Fuente: elaboración propia.

23 Dentro de la complejidad, destacamos que esta zona se convierte en una de las de más difícil control, inclusive para comunidades y resguardos indígenas como el pueblo Awá, que mantiene una serie de estrategias de protección del territorio. La presencia de este pueblo muestra la heterogeneidad de esta área y las tensiones existentes, que no son objeto de estudio de esta investigación. 
Tanto las dinámicas transnacionales como las nacionales y las locales ponen de relieve la estructura social y necropolítica de interés, la cual se revela con múltiples elementos que, infortunadamente, pueden cohabitar con fenómenos tales como la actual pandemia de COVID-19.

\section{COVID-19 en el border tumaqueño. Entre la guerra y la sobrevivencia}

La presente investigación no ofrece un panorama comparativo entre Tumaco antes y durante la pandemia, ${ }^{24}$ pues su interés es mostrar cómo la construcción estructural y las violencias asociadas a ellas pueden recrudecer ciertos efectos, bajo una lógica capitalista con un marcador profundamente racial. A la luz de los tres elementos planteados en el perfil (geografía, sujetos endriagos y border) que operan como las coordenadas estructurales necropolíticas de Tumaco, a continuación planteamos los efectos de la pandemia con base en datos obtenidos fundamentalmente de informes de organizaciones no gubernamentales y dos testimonios clave. ${ }^{25}$

Como mencionamos anteriormente, Tumaco, al igual que otros municipios del Pacífico (Timbiquí, Quibdó o Buenaventura, por ejemplo), son geografías de pobreza marcadas por una profunda lógica de raza y clase. En estas geografías, el Estado, desde su ausencia legal y presencia ilegal, "determina quién debe vivir y quién es prescindible; se combina el biopoder clásico y la necropolítica” (Mbembe, 2011, p. 46). Contrario al planteamiento de Foucault en el que el Estado era el único que podía matar, “en la propuesta necro también el capital trasnacional puede ha-

24 Aunado a la dificultad que representa para los investigadores viajar a territorio para realizar trabajo de campo.

25 Aclaramos que los testimonios usados anteriormente en dos de las notas a pie de página no representan una metodología de nuestra investigación, simplemente son utilizados para enriquecer los argumentos expuestos a la luz de la experiencia de las personas entrevistadas. Beiron es un líder comunitario de la zona, mientras que María Fernanda se desempeñó como bacterióloga del Hospital San Andrés de Tumaco, durante el periodo de marzo a septiembre del año 2020. 
cerlo, son fronteras políticas internas y externas” (Mbembe, 2011, p. 60). Es aquí donde se configuran el capitalismo gore y las necroprácticas.

Constatar las prácticas tanáticas en nuestra unidad de análisis puede ser un ejercicio infortunadamente sencillo, partiendo de la serie de masacres acontecidas en los últimos años. ${ }^{26}$ De estas, el 80\% muestran una relación directa con el narcotráfico, y la mayoría tienen por objeto cuerpos negros o incluso cuerpos de ciudadanos ecuatorianos que presuntamente participaban en el tráfico de drogas. Estas dinámicas de violencia cobran sentido en la etno-diferencialidad ${ }^{27}$ de los actores que tienen una presencia importante en la zona.

Dichas desigualdades estructurales y violencias existentes han generado grietas sociales y multiplicación de riesgos que permiten la introducción progresiva de otro tipo de crisis regionales, que contemporáneamente pueden ser leídas a la luz de la pandemia de COVID-19. ${ }^{28}$

26 Para ejemplificar esto, véanse: Informe de masacres en Colombia durante el 20202021, realizado por el Instituto de Estudios para el Desarrollo y la Paz (INDEPAz), disponible en http://www.indepaz.org.co/informe-de-masacres-en-colombia-durante-el-2020/; Gobernador de Nariño denuncia masacre de seis jóvenes en Tumaco, disponible en https://www.eltiempo.com/colombia/otras-ciudades/masacre-deseis-jovenes-en-tumaco-narino-denuncia-el-gobernador-532086; Masacre en Tumaco: cinco personas fueron asesinadas, disponible en https://www.elespectador.com/ noticias/nacional/masacre-en-tumaco-cinco-personas-fueron-asesinadas-articulo-916332/; Especial - Tumaco llora una masacre "en tiempos de paz", disponible en https://www.contagioradio.com/tumaco-llora-una-masacre-en-tiempos-de-paz/

27 Asumimos la etno-diferencialidad como la categoría que analiza la diferencia étnica y cultural de los individuos bajo un principio de autoidentificación en alguna de las categorías pensadas por el Estado. Esta etno-diferencia es heredera de los estudios que profundizan en la configuración étnico-racial de la sociedad, con lo cual se analizan los grupos humanos y las igualdades/desigualdades que pueden experimentar (Viáfara y Serna, 2015).

28 En Colombia las comunidades autoidentificadas como afrocolombianas, negras, raizales y palenqueras pueden resumir su presencia demográfica en dos zonas específicas: la zona Atlántica y la zona Pacífica. La primera se extiende hasta el Caribe abarcando a las comunidades raizales y palenqueras de municipios como San Andrés Isla o el corregimiento San Basilio de Palenque. Todas estas enfrentan una serie de desigualdades socioeconómicas, escolares y de salud, las cuales han 
El primer caso de COVID-19 en Tumaco se registró el 31 de marzo de 2020; al mes de noviembre del mismo año - fecha de escritura de esta investigación-, se contabilizan en el municipio más de 2000 casos positivos. En su inicio, este fenómeno representó para Tumaco una crisis humanitaria inminente en el sector salud, ya que solo cuenta con un hospital de segundo nivel que debe atender a aproximadamente 400 000 usuarios de los diez municipios de la costa y los dos del piedemonte costero de Nariño. ${ }^{29}$

La multiplicación de los riesgos se hizo evidente al situar la adversidad de este fenómeno en todo el Pacífico con un marcador étnico-racial. El médico y epidemiólogo Yoseth Ariza, en estudio realizado en el marco de la Alianza Pacífico Task Force, encontró que las personas que se autorreconocen como negras, afrocolombianas, raizales y palenqueras, una vez contraen el virus tienen más probabilidades de tener desenlaces negativos que la población que no se reconoce con ninguna etnia” (citado en Naranjo, 2020, párr. 3).

Los análisis de esta iniciativa, así como otros esfuerzos paradójicamente desarrollados por el Estado, encontraron que los informantes que se autoidentifican como afrodescendientes, raizales o palenqueros tienen $96 \%$ más probabilidades de ser hospitalizados, $316 \%$ más probabilidades de terminar en unidades de cuidados intensivos y $28 \%$ más riesgo de morir, si se comparan con la población no étnica. ${ }^{30}$

sido analizadas desde la academia y las organizaciones de la sociedad civil fundamentalmente (Telles, Flores y Urrea-Giraldo, 2015).

29 Estos hospitales no cuentan con la infraestructura ni la capacidad para suplir la demanda, no hay camas disponibles, ni especialistas permanentes, lo cual genera que los pacientes sean remitidos a la ciudad de Pasto para recibir un servicio de salud digno (Casa de la Memoria, 2016).

30 Adicionalmente, la no existencia de servicios de agua potable, saneamiento básico e higiene y el clima tropical permiten la proliferación de mosquitos y exponen a la población a mayores riesgos de infección respiratoria, dengue, paludismo, entre otras enfermedades. De acuerdo con Macías y Abello (2020), al 11 de junio del 2020 Tumaco tenía el 56,22\% de los casos reportados en el departamento, con la 
Otro de los elementos relacionados con la geografía de la pobreza es el hacinamiento de los hogares. La mayoría de los hogares del casco urbano están compuestos por familias extensas, de las cuales alrededor del $69 \%$ vive en casas con uno o dos dormitorios. Bajo esta dinámica, el aislamiento de una persona con diagnóstico positivo a la enfermedad es prácticamente imposible y el riesgo de contagio al núcleo familiar es enorme. Además, alrededor del $80 \%$ de la población subsiste gracias a la economía informal, el rebusque, la venta de alimentos, el mototaxismo, entre otras actividades no reguladas que la exponen al contagio en las calles y a su regreso a casa.

En coordenadas de border, hallamos una dificultad por parte del Estado legal y administrativo para articular de manera efectiva una estrategia biopolítica en clave de protección del cuerpo social. ${ }^{31}$ Ante las colosales cifras de contagios en Ecuador, una gran cantidad de personas ingresaron a Tumaco por medio marítimo y terrestre, siendo este uno de los factores por los cuales este es el municipio con más contagios de Nariño. ${ }^{32}$

Sobre la producción de los sujetos endriagos, los jóvenes están más expuestos a involucrarse en una de las actividades criminales para así participar directamente en los grupos distópicos que los definen. Estos grupos criminales, conformados por sujetos endriagos que se disputan el territorio, han ganado ventaja ante la situación producto de la pandemia COVID-19, engrosando sus filas fundamentalmente con jóvenes

dolorosa cifra de 1143 personas contagiadas, lo cual lo señalaba como el municipio con mayor propagación del virus en Nariño.

31 La Alcaldía Municipal, durante el inicio de la pandemia, mostró su incapacidad como gobierno local para establecer control y monitoreo sobre la COVID-19, especialmente en la frontera.

32 Adicionalmente, las ayudas humanitarias son dadas por conveniencia política, permitiendo que las familias más afectadas se vean expuestas a una doble vulnerabilidad: la primera relacionada con las condiciones de pobreza que ante el aislamiento se profundizan; y la segunda asociada a la exposición obligatoria por razones de sobrevivencia. 
masculinos. Como se ha evidenciado en algunas zonas rurales de Colombia en las que bandas criminales han reclutado jóvenes y menores para sus grupos armados durante la pandemia (Camargo, 2020), algunos barrios vulnerables urbanos de Tumaco, como el Nuevo Milenio, han experimentado un incremento en el reclutamiento de jóvenes afrodescendientes por parte de los llamados grupos al margen de la ley (Beiron, comunicación personal, 2020).

Por otro lado, en diversas fuentes se habla del impacto que ha tenido la crisis humanitaria en el grueso de la población, pero existe muy poca información sobre las condiciones en las que el personal de la salud debe ejercer, y sobre la exposición sanitaria y de seguridad a la que se debe someter en un contexto de constante conflicto. Al interior de las estructuras necropolíticas que permean todas las esferas sociales en los niveles expuestos, operan instituciones del sistema de salud en donde persiste la zozobra que vive el personal, producto del temor por su integridad al trabajar en un hospital situado en una zona con alta presencia de sujetos endriagos, situación que contrasta con la presión de no dejar perder vidas que estén asociadas a estos grupos ilegales, porque ello también les implicaría perder la propia. El personal médico se enfrenta, además, al dilema ético de definir quién debe acceder a los recursos del sistema de salud y quién no, es decir, a ejercer el biopoder al momento de dejar vivir o dejar morir (Arribas, Cano, y Ugarte, 2010), dependiendo de los capitales simbólicos y económicos de la persona en situación de urgencia.

Por último, y en aras de constatar la vigencia de los ejercicios tanáticos en estas geografías, es decir, las violencias directas que tienen como fin el homicidio, desde la fecha del registro del primer infectado hasta el mes de noviembre, en Tumaco se han cometido alrededor de 30 masacres que han cobrado la vida de menores de edad presuntamente implicados en lógicas de narcotráfico, de firmantes del acuerdo de paz, y de líderes y lideresas sociales (Quiñones y Daza, 2020). Estos mínimos datos corroboran nuestro argumento central: la pandemia, en el border 
tumaqueño, es un fenómeno que cohabita e incluso recrudece los efectos de la COVID-19. ${ }^{33}$

\section{Conclusiones}

Lo político tanto para Foucault como para Mbembe y Valencia es una relación de guerra y violencia como continuación de su ejercicio y como práctica de soberanía. En su lectura clásica esta guerra es ejercida contra cuerpos específicos que afecten o pongan en riesgo el cuerpo social biológico y normalizado. En clave necropolítica, la guerra dirige sus efectos contra cuerpos racializados y feminizados, mediante necroprácticas que hacen operar el consumo de la violencia. El capitalismo gore, como condición de existencia situada espacialmente, vulnera a cuerpos específicos desde lo estructural, pasando incluso por lo simbólico. Si bien la autora mexicana Sayak Valencia plantea que las mujeres son el primer objeto de guerra, para nuestra unidad de análisis (Tumaco) y en clave de nuestros intereses, los cuerpos negros en la frontera sur son los más vulnerados.

Por lo tanto, en el marco propio de los Sur Globales, vale la pena cuestionar el recrudecimiento de la extrema vulnerabilidad, así como los efectos de las crisis y las coyunturas en los territorios con intersecciones relevantes como clase, raza y género; geografías objeto del olvido del Estado legal y muchas veces de la presencia del narcoestado ilegal. En el desarrollo de esta investigación optamos por tomar diversas acepciones de violencia contra cuerpos racialmente definidos, pues, siguiendo a Vera (2015), "es claro que problemas como la violencia racial, étnica, cotidiana y estructural están aún lejos de ser parte de un diagnóstico generalizado del problema de la violencia en Colombia y de políticas públicas para enfrentarla” (p. 263).

33 Además, se han cometido una serie de violencias contra mujeres; sin embargo, la información sobre esto aún es escasa y difícil de constatar, más allá de algunos testimonios obtenidos. 
Geografías como la del municipio de Tumaco responden a las lógicas capitalistas que reproducen una segregación étnico-racial y permiten la reproducción de desigualdades estructurales sociales y económicas en este territorio. Así mismo, evidencian el control y administración de la vida de los integrantes de estos grupos humanos, es decir, se ejerce el biopoder sobre estos cuerpos racializados en condiciones de vulnerabilidad. Si bien no hay una participación directa del Estado en su versión de racismo clásico, sí persisten estructuras amparadas en su omisión. ${ }^{34}$

Tanto los sujetos endriagos presentes en la zona como la condición border multiplican los riesgos socioespaciales, así como las dinámicas que derivan de la circulación de mercancías ilícitas en contextos urbanos y rurales. Ante esto, Tumaco se convierte en un foco de atención complejo y cuestionable desde todos los marcos.

Desde que en Tumaco se conoció el primer caso de un habitante contagiado por COVID-19, a la fecha, se ha mantenido la existencia de grupos armados y la persistencia de masacres producto de los ejercicios necropolíticos. Incluso, las filas de los actores armados paradójicamente se han engrosado. A esto se le suma la desprotección al personal del área de la salud, el cual debe ejercer en condiciones de precarización laboral y violencia constante, generando incluso otras escalas del hacer vivir y dejar morir.

Finalmente, si bien esta investigación ha sido una propuesta fundamentalmente conceptual, consideramos que la extrema vulnerabilidad de los habitantes, leídos bajo una etno-diferencialidad, se convierte en un llamado de atención ante una relación compleja de falta de reconocimiento y necesidad de garantizarles los derechos fundamentales por parte del gobierno departamental, puesto que según líderes y lideresas

34 Es responsabilidad del Estado, pues los problemas específicos de la vida y de la población, como la sexualidad, reproducción, trabajo, salud, higiene, vivienda, etc., son subsumidos en el seno de la administración estatal (Giraldo, 2006, p.116). 
del municipio permanece la exclusión social de las comunidades negras. A pesar de que este tipo de desigualdades han sido ampliamente examinadas, consideramos que un análisis conceptual como el que presentamos puede aportar otras formas de entender las violencias suscitadas en la región.

\section{Referencias}

Álvarez, María. (2013). Desigualdad en Colombia. Iberoamericana, 13(51), 190-195. DOI: http://dx.doi.org/10.18441/ibam.13.2013.51.190-195

Alves, Jaime. (2020). Biopólis, necrópolis, "blackpolis": notas para um nuevo léxito em los análisis socio-espaciales del racismo. Geopauta, 4(1), 5-33.

Alves, Jaime y Ravidran, Tathagatan. (2018). Los condenados de la ciudad: insurgencia espacial negra en dos ciudades de América Latina. Documentos de trabajo, Grupo Interseccionalidades, Cali.

Angulo, Alejandro y López, Daniela. (2018). Tumaco, de paraíso a infierno. Recuperado de https://www.cinep.org.co/publicaciones/PDFS/20181201_articulo10.pdf

Arribas, Sonia; Cano, Germán y Ugarte, Javier (Coords.). (2010). Hacer vivir, dejar morir. Biopolítica y capitalismo. Madrid: Consejo Superior de Investigaciones Científicas.

Asesinan a sospechoso de la muerte de tres niñas en Tumaco. (2 de agosto de 2016). Periódico La Última. Recuperado de https://periodicolaultima.com/2016/08/02/asesinan-a-sospechoso-de-la-muerte-de-tres-ninasen-tumaco/

Bitácora \& Territorio. (2017). Lectura territorial de San Andrés de Tumaco. Bogotá: Centro Latinoamericano para el Desarrollo Rural/Fondo Internacional de Desarrollo Agrícola.

Camargo, Carlos. (1 de diciembre de 2020). El reclutamiento de menores continúa durante la pandemia: Defensoría del Pueblo. Recuperado de https:// www.infobae.com/america/colombia/2020/12/01/el-reclutamiento-demenores-continua-durante-la-pandemia-defensoria-del-pueblo/ 
Casa de la Memoria. (6 de diciembre de 2016). La lenta agonía del Hospital San Andrés de Tumaco. Recuperado de https://casamemoriatumaco.org/ la-lenta-agonia-del-hospital-san-andres-tumaco/

Departamento Administrativo Nacional de Estadística. (2000). Concepto básicos. Bogotá: Autor. Recuperado de: https://www.dane.gov.co/files/inf_ geo/4Ge_ConceptosBasicos.pdf

Departamento Administrativo Nacional de Estadística. (2005). Informe general del censo poblacional. Bogotá: Autor.

Estévez, Ariadna. (2018). Biopolítica y necropolítica: ¿constitutivos u opuestos? Espiral, Estudios sobre Estado y Sociedad, 25(73), 9-45. DOI: https:// doi.org/10.32870/espiral.v25i73.7017

Foucault, Michel. (2001). Defender la sociedad. México, D. F.: Fondo de Cultura Económica.

Ideas para la Paz. (2014). Área de dinámicas del conflicto y negociaciones de paz. Boletín sobre Negociaciones de Paz y Justicia Transicional (69).

Galvis, Luis; Moyano, Lina y Alba, Carlos. (2016). La persistencia de la pobreza en el Pacífico colombiano y sus factores asociados. Recuperado de: https:// www.banrep.gov.co/docum/Lectura_finanzas/pdf/dtser_238.pdf

Giraldo, Reinaldo. (2006). Poder y resistencia en Michel Foucault. Tabula Rasa, (4), 103-122. Recuperado de http://www.scielo.org.co/pdf/tara/n4/n4a06.pdf

Gusis, Gabriela. (2018). Criminología y racismo: a propósito de las políticas necro-criminales a los inmigrantes. Revista Derechos en Acción, 9(9), 266-289.

La droga se refina en Tumaco y llega al Ecuador. (25 de abril de 2017). El Comercio. Recuperado de https://www.elcomercio.com/actualidad/drogatumaco-colombia-ecuador-estadosunidos.html

López, Cristina. (2014). La biopolítica según la óptica de Michel Foucault: alcances, potencialidades y limitaciones de una perspectiva de análisis. El banquete de los dioses. Revista de filosofía y teoría política contemporáneas, 111-137.

López, Flor (Coord.). (2017). Geografía y pobreza. Nuevos enfoques de análisis espacial. México, D. F.: Universidad Nacional Autónoma de México. 
Lozano, Betty. (2016). Asesinato de mujeres y acumulación global: el caso del bello Puerto del Mar mi Buenaventura. Recuperado de http://observatoriofeminicidioscolombia.org/attachments/article/255/Betty-Ruth-LozanoASESINATO-DE-MUJERES-Y-ACUMULACI\% C3\% 93N-GLOBAL.pdf

Macías, Lina y Abello, Daniel. (14 de junio de 2020). Pandemia y corrupción: la tragedia humanitaria en Tumaco. PARES Fundación Paz y Reconciliación. Recuperado de https://pares.com.co/2020/06/14/ entre-pandemia-y-corrupcion-la-tragedia-humanitaria-en-tumaco/

Mbembe, Achile. (2011). Necropolítica. Barcelona: Editorial Melusina.

Moreno, Isidro. (1994). ¿Violencia étnica o violencia de Estado? Nacionalismos estatalistas, neonacionalismos y minorías étnicas. En José Antonio Fernández, Etnicidad y violencia (pp. 137-156). La Coruña: Universidad de Coruña.

Naranjo Navarro, Juan David. (3 de agosto de 2020). ¿Por qué la COVID-19 se ensaña contra la población afro? Semana rural. Recuperado de https://semanarural.com/web/articulo/como-afecta-el-coronavirus-alos-afro-en-colombia/1541

Oya, Carlos y Sender, John. (2007). Pobreza y empleo en África Subsahariana: mitos y realidades. En Antonio Santamaría, Eduardo Bidaurratzaga, Christopher Cramer, Bill Freund, Edward Lahiff, Peter Lawrence, Carlos Oya, John Sender y John Weeks, Economía Política del Desarrollo en África. Madrid: Ediciones Akal.

Palacios, Beiron. (2020). Comunicación personal a través de la plataforma Meet.

Quiñones, Ivonne y Daza, Francisco. (7 de septiembre de 2020). Alerta roja en Nariño, siete masacres en época de pandemia. PARES Fundación Paz y Reconciliación. Recuperado de https://pares.com.co/2020/09/07/ alerta-roja-en-narino-siete-masacres-en-los-ultimos-meses/

Salazar, Salvador. (2014). Subjetividades disidentes y el (des) dominio del bipoder paralegal: la producción sociocultural de los cuerpos en Ciudad Juárez, México. Culturales, 2(2), 157-177.

Sistema Integrado de Monitoreo de Cultivos Ilícitos-Oficina de las Naciones Unidas contra la Droga y el Delito. (Septiembre, 2018). Informe de mo- 
nitoreo de territorios afectados por cultivos ilícitos en Colombia (2017). Bogotá: Autores. Recuperado de https://www.unodc.org/documents/ colombia/2018/Octubre/INFORME_MONITOREO_DE_CULTIVOS_ ILICITOS_2017_FINAL.pdf

Souza, Boaventura de y Meneses, María. (2014). Epistemologías del Sur. Madrid: Ediciones Akal.

Telles, Edward; Flores, René y Fernando, Urrea-Giraldo. (18 de febrero de 2015). Pigmentocracies: Educational inequality, skin color and census ethnoracial identification in eight Latin American countries. Research in Social Stratification and Mobility, (40), 39-58.

Tercero, Magali. (2013). Vida cotidiana y narcotráfico. Revista Digital Narco Machine. Recuperado de http://hemi.nyu.edu/hemi/es/e-misferica-82/ tercero

Valencia, Sayak. (2010). Capitalismo Gore. Barcelona: Editorial Melusina.

Van Dijk, Teun. (1997). Racismo y análisis crítico en los medios. Barcelona: Paidós.

Vasil'eva, Jana; Centmayer, Helena; Del Valle, Oscar y Maya, Lucía. (2016). Violencia de género y feminicidios en el Estado de México. La percepción y las acciones de las organizaciones de la sociedad civil. México: Centro de Investigación y Docencia Económicas.

Vera, Juan. (2015). Antropología y “estudios de la violencia” en Colombia: en busca de una perspectiva crítica. Revista Colombiana de Antropología, 51(1), 245-269.

Viáfara, Carlos y Serna, Nini. (2015). Desigualdad de oportunidades educativas en la población de 15 a 29 años en Brasil y Colombia según autoclasificación étnico-racial. Sociedad y Economía, (29), 151-174.

Zaffaroni, Raúl. (2012). La cuestión criminal. Buenos Aires: Planeta.

Zúñiga, Yanira. (2018). Cuerpo, Género y Derecho. Apuntes para una teoría crítica de las relaciones entre cuerpo, poder y subjetividad. lut et Praxis, 24(3), 209-254. 